\title{
Peri-operative pain in patients experiencing bariatric surgery
}

\author{
N. Kumar ${ }^{1,5 *}$, D. Soekarman ${ }^{2,5}$, R. Singh ${ }^{3}$, M.M. Bashah ${ }^{4,5}$, A.B. Abou Samra ${ }^{2,5}$ and M.A.E. Marcus $^{1,5}$ \\ ${ }^{1}$ Department of Anesthesiology, ICU and Perioperative Medicine, Hamad General Hospital, Doha, Qatar \\ ${ }^{2}$ Department of Medicine, Hamad General Hospital, Doha, Qatar \\ ${ }^{3}$ Heart Hospital, Qatar \\ ${ }^{4}$ Department of Surgery, Bariatric Team, Hamad General Hospital, Doha, Qatar \\ ${ }^{5}$ Weill Cornell Medicine, Qatar
}

\begin{abstract}
A review of the literature was performed to identify follow-up studies on pain and bariatric surgery (gastric band, gastric sleeve or R-en-Y gastric bypass) as intervention. The main objective of this study was to find information on the prevalence of chronic pain in patients undergoing any of the mentioned surgical techniques and the incidence of chronic postsurgical pain after bariatric surgery.

16 studies were included for further analysis with over 2000 subjects. $2 / 3$ of the information was on bypass surgery. "Short term" studies with data on pain within 3 months after surgery were randomized controlled trials (RCTs) comparing surgical techniques or analgesia. Pre-operative pain status had not been documented. However, peri-operative pain management was reported in detail. In 8 observational studies, pain data were available exceeding 3 months after surgery ("long term" studies). While pre-operative pain data were reported in the latter studies, in over half the anatomic location of the pain had not been specified.

An accurate estimation of the incidence of chronic postsurgical pain after bariatric surgery was not possible based on the available data. The number of comparable studies was low and the anatomic location of the pain had not been specified. Data on pain between 1 week and 6 months after surgery are lacking. This period is important, since it contains the time point after which the measured pain can be defined as chronic.
\end{abstract}

\section{Introduction}

The number of patients undergoing a bariatric procedure for weight loss is still increasing, and nowadays also less overweight individuals are offered this treatment modality for conditions such as diabetes and the metabolic syndrome [1]. Improving its success rate requires attention for all post-surgical factors that hamper recovery and maintenance of weight loss over time. One of these factors might be chronic postsurgical pain (CPSP) [2-4].

Chronic postsurgical pain (CPSP) has been defined as pain persisting for more than 3 months after expected healing time [5]. Measuring chronic pain after surgery might involve up to 3 pain curves in an individual patient, depending on the time point of pain assessment [6]. In such a model, pre-operative and/or chronic postsurgical pain might be an issue in addition to the acute pain due to surgery. Patients planned for bariatric surgery for weight reduction, already suffer from a high prevalence of chronic pain conditions [7]. Abdominal discomfort might be a problem, as a pre-existing chronic condition or as surgeryrelated pain [8]. CPSP of the surgical site after bariatric surgery has been reported in up to $50 \%$ of the patients [9-11].

We are interested whether a transition from acute to chronic pain might contribute to postoperative complications requiring further attention. The focus of the literature search was on band, sleeve or bypass as surgical techniques, reportedly in use in most bariatric centers.

\section{Methods}

The Pubmed, Cochrane and EMBASE databases were searched with search items "Bariatric surgery and pain or obesity surgery and pain or gastric band and pain or gastric sleeve and pain or gastric bypass and pain" according to the guidelines by Liberati, et al. ([12], Figure 1) (closing date of the search: 26.07.2016). Abstracts in the English language were included for further analysis if the title indicated that a qualitative or quantitative analysis of pain in subjects, undergoing either of the mentioned surgical techniques had been performed (Phase 1 in figure S1). Case reports (as mentioned in the title or abstract), studies with a focus on re-operation or where subjects had simultaneous surgery for another indication were excluded.

Full text publications in the English language were analyzed for the study of pain and included if the pain-status had been documented at minimally three defined points in time in the same individual using the same pain assessment tool, and if data on pain were represented either in a graph or a table, or both (Phase 2 in figure S1). The surgical technique used should have been specified in relation to the reported data on pain. References from full-text publications were retrieved and included if of relevance ("cross references"). Reports with discrepancies between text and tables/figures were excluded.

Correspondence to: Neeraj Kumar, MD, MM. Assistant Professor, Department of Anesthesiology, ICU and Perioperative Medicine, Weill Cornell Medicine, Hamad General Hospital, Doha, Qatar, Tel: +97444391763; +97455611716, E-mail:nkumar@hamad.qa

Key words: chronic postsurgical pain, gastric band, gastric sleeve, quality of life, roux-en-y gastric bypass

Received: May 25, 2017; Accepted: June 12, 2017; Published: June 15, 2017 

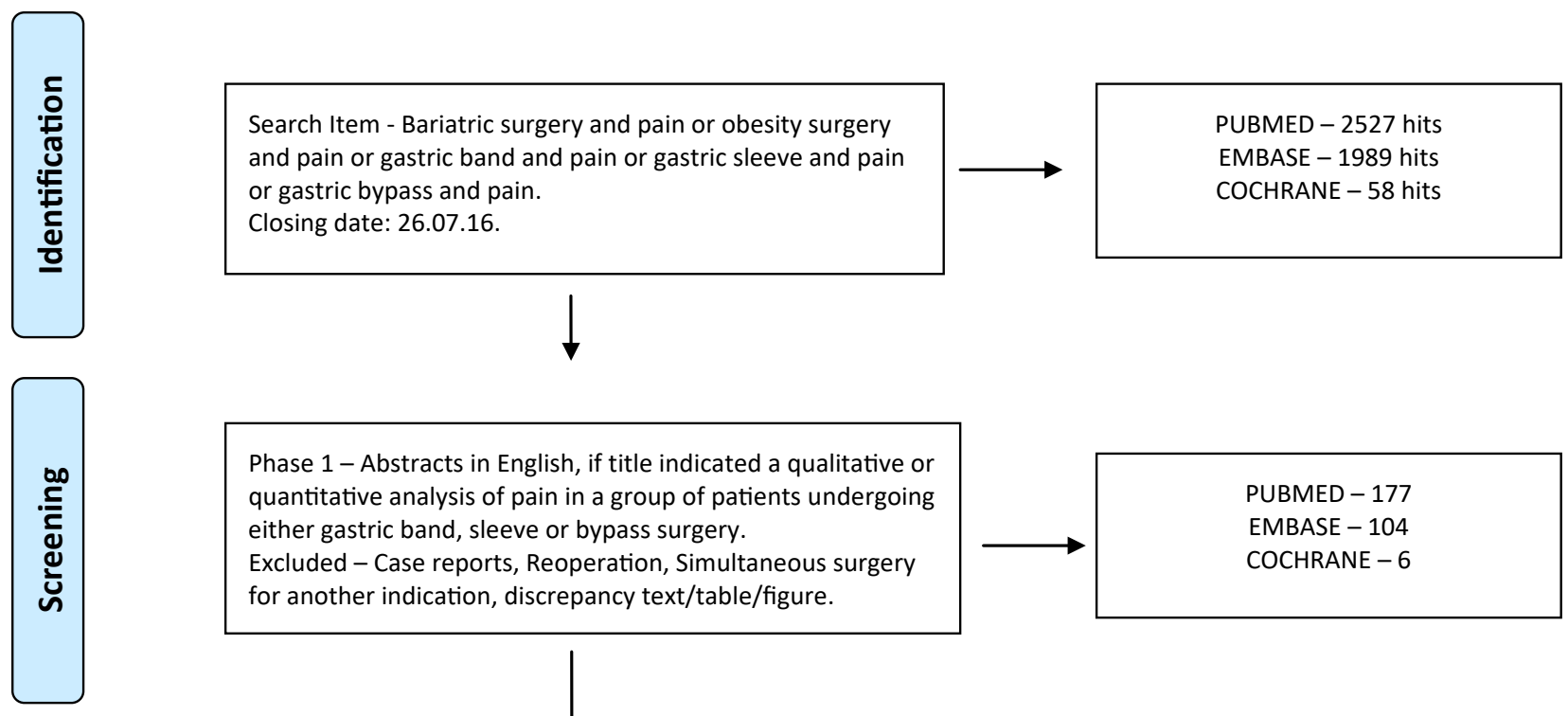

Phase 1 - Abstracts in English, if title indicated a qualitative or quantitative analysis of pain in a group of patients undergoing either gastric band, sleeve or bypass surgery.

Excluded - Case reports, Reoperation, Simultaneous surgery for another indication, discrepancy text/table/figure.

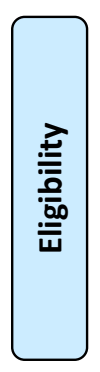

Phase 2 - full text included if the pain-status had been documented at three different points in time in the same individual, and if data were represented either in a graph or a table.
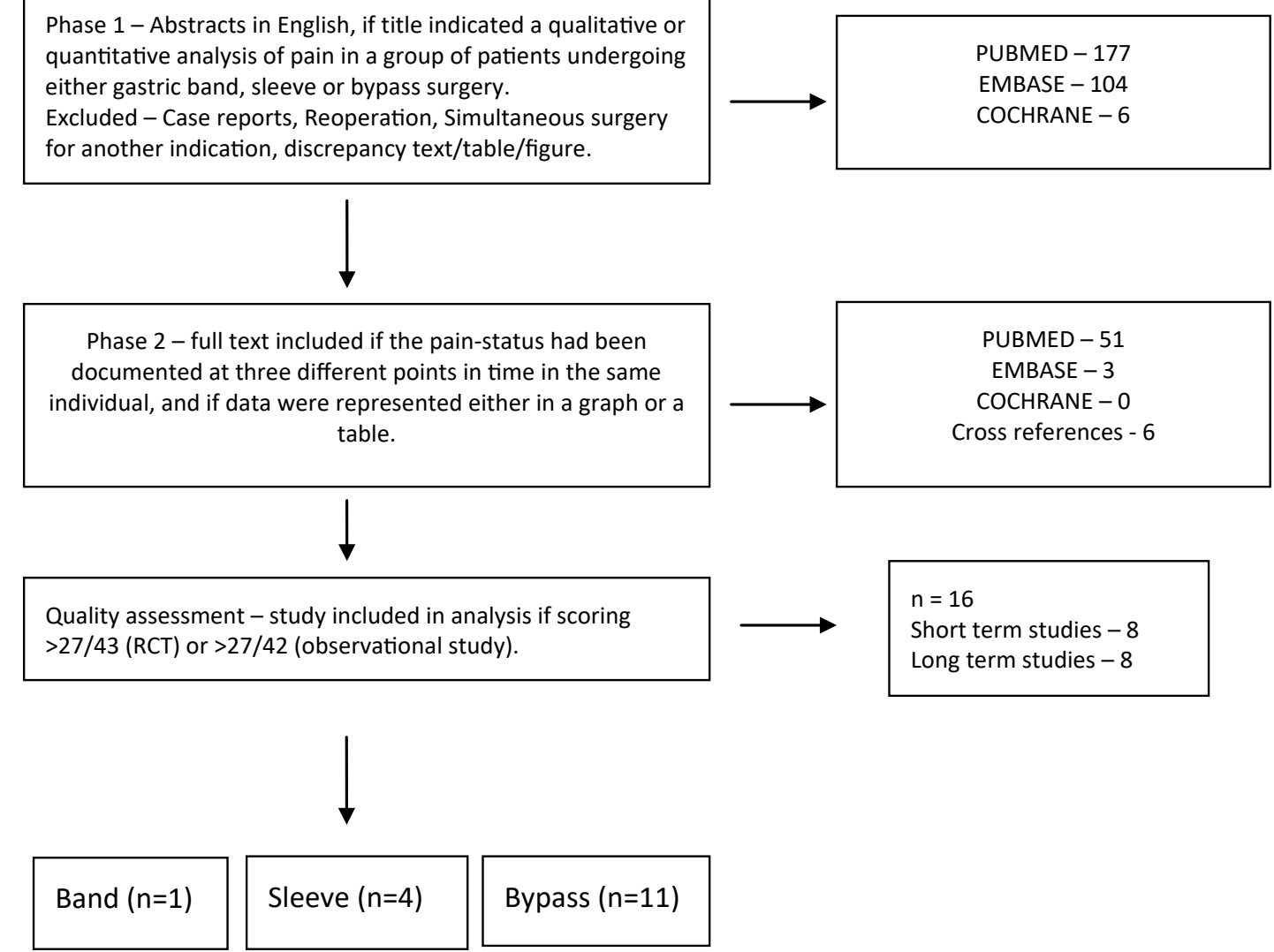

Figure 1: Prisma flow diagram.

Quality assessment was performed using a combination of adapted assessment tools for health care interventions, randomized controlled trials (RCTs) involving pain management and observational studies of interventional pain management [13-15]. Studies scoring over $65 \%$ were included for final analysis. Details on the adapted checklists can be found in the addendum. Lists of phase 1 and phase 2 references, and the scoring of the 60 phase 2 publications are obtainable from the authors on request.

\section{Results}

Sixteen from 60 phase 2 studies scored over $65 \%$ and were included for further analysis (Table 1) [16-31]. Pain had been measured and recorded in over 2000 subjects in randomized controlled trials (RCT, $n=7)$ or observational studies $(n=9)$. Two publications shared (part of) the same cohort $[28,29]$. Most references were found for the R-en-Y gastric bypass technique (including over 1700 subjects), followed by the band and sleeve techniques. In 8 "short-term" studies, data on pain were obtained within 3 months after surgery. The pain was scored on a 0 to 10 scale $(10=$ most pain) within one week after surgery by an observer or the subject. In 8 "long-term" studies, data on pain were provided for the postoperative period exceeding 3 months. In these studies, the pre-operative pain status was reported as well. However, no further information on the location of the pain under investigation was provided in over half of these studies. While peri-operative pain management had been recorded in the short-term studies, such information was not available in the long-term studies (data not shown). Further meta-analysis on these 16 studies was not performed, due to the small number of studies with comparable study methodology. 
Table 1. Phase 2 studies after quality assessment $(n=16)$.

\begin{tabular}{|c|c|c|c|c|c|c|c|}
\hline & $\begin{array}{l}\text { Study } \\
\text { type }\end{array}$ & $\begin{array}{l}\text { surgical } \\
\text { technique }\end{array}$ & Subjects & Pain assessment tool & $\begin{array}{l}\text { Pre-operative } \\
\text { data on pain }\end{array}$ & $\begin{array}{c}\text { Last time point } \\
\text { of pain assessment }\end{array}$ & Drop out \\
\hline Short term studies & & & $\mathrm{N}=590$ & & & & \\
\hline Cabrera Schulmeyer et al., 2010 & RCT & lap sleeve & 80 & VAS & no & $24 \mathrm{hrs}$ & $<10 \%$ \\
\hline Naja et al., 2014 & $\mathrm{RCT}$ & lap sleeve & 60 & VAS & no & $24 \mathrm{hrs}$ & not mentioned \\
\hline Cleveland et al., 2015 & $\mathrm{RCT}$ & lap sleeve & 82 & VAS & no & $32 \mathrm{hrs}$ & no details \\
\hline Hassani et al., 2015 & $\mathrm{RCT}$ & lap bypass & 60 & VAS & no & $6 \mathrm{hrs}$ & $0 \%$ \\
\hline Zeidan et al., 2013 & Obs & lap bypass & 114 & NRS & no & $24 \mathrm{hrs}$ & $16 \%$ \\
\hline Albrecht et al., 2013 & RCT & lap bypass & 57 & NRS & no & 2 days & $<10 \%$ \\
\hline Weingarten et al., 2015 & $\mathrm{RCT}$ & lap bypass & 89 & NPS & $15 / 42$ migraine & $<1$ week & $<20 \%$ \\
\hline Zotou et al., 2014 & $\mathrm{RCT}$ & open bypass & 48 & VAS & no & 2 days & $0 \%$ \\
\hline Long term studies & & & $\mathrm{N}=1519$ & & & & \\
\hline Novack et al., 2011 & Obs & gastric band & 29 & MIDAS & yes & 6 months & $<30 \%$ \\
\hline Burgerhart et al., 2015 & Obs & lap sleeve & 20 & VAS & no & 2 years & no details \\
\hline Lloret-Linares et al., 2014 & Obs & lap bypass & 30 & pain threshold & yes & 6 months & $20 \%$ \\
\hline Ballem et al., 2009 & Obs & lap bypass & 763 & GI questionnaire & yes & 5 years & $>95 \%$ \\
\hline Brissman et al., 2016 & Obs & lap bypass & 41 & $\%$ of subjects with pain & yes & 2 years & $32 \%$ at baseline \\
\hline Olbers et al., 2012 & Obs & lap bypass & 81 & SF36 & yes & 2 years & $0 \%$ \\
\hline Risstad et al., 2015 & Obs & lap bypass & 232 & SF36 & yes & 2 years & $56 \%$ \\
\hline Kolotkin et al., 2012 & Obs & bypass & 323 & SF36 & yes & 6 years & $39.60 \%$ \\
\hline
\end{tabular}

Lap: laparoscopic; Obs: observational; Continuous: continuous symptoms; GI: Gastro-intestinal questionnaire

\section{Discussion}

Chronic pain after bariatric surgery for weight reduction is mainly analyzed in quality of life studies measuring bodily pain [32,33]. Improvement in general well-being is observed as early as 3 to 6 months after surgery $[31,34,35]$. While an initial increase in quality of life with a decrease in bodily pain is reported in the first year after surgery, contradictory observations are made in the few studies on larger cohorts of patients with specification of the pain location. Steele et al reported an increase in abdominal pain in the first year after surgery [36]. Data were derived from an administrative database including over 20,000 subjects undergoing bariatric surgery. Ballem, et al. showed an initial decrease followed by a slow increase in pain back to baseline levels 5 years after surgery in a survey of over 750 individuals undergoing laparoscopic bypass surgery [27]. In this latter study, the retention of subjects in later years was an issue, while in the former study the surgical technique that had been used, was not specified. Such information is important if studying postsurgical pain. Specific surgical techniques might influence recovery time in the acute postoperative period [37-39]. The length of pain exposure in the acute postoperative period is associated with the development of chronic postsurgical pain [40,41]. Optimal pain reduction in the acute postoperative period seems to be important, not only for fast recovery and rehabilitation in the short-term, but for the prevention of CPSP as well [42,43].

Treating acute pain after surgery appropriately, disguises its postoperative curve. This complicates the interpretation of the data obtained from the ample RCTs in bariatric surgery, which are mainly focused on pain reduction. A few studies indicate that recovery from acute pain after surgery might take place as early as 1 week after the band or sleeve technique [44,45]. However, at least $10 \%$ of the patients seem to remain at risk for CPSP after sleeve or bypass surgery [46,47].

While a substantial number of studies report data on peri-operative pain in relation to bariatric surgery, only part meets current quality criteria for randomized controlled trials or observational studies $[14,15]$. Additional research is needed with prospectively collected data using comparable pain assessment tools and performing follow-up with retention of subjects [5]. In such studies, the anatomic location of the pain should be taken into consideration to be able to interpret the obtained data appropriately. Sufficient time points of pain assessment should be included to be able to study the postoperative pain curve adequately. Pain assessment between 1 week and 6 months after surgery deserves more attention since this period contains the conversion point after which the measured pain can be defined as chronic.

Traditionally, bariatric surgery has been reserved for those with major overweight not responding to diet and life style programs. Nowadays, surgery is also offered to those with metabolic morbidities, despite less overweight. In such patients, the balance between risks and benefits from surgery might even be more precarious, justifying the further exploration of postoperative complications such as pain.

\section{Disclosure}

Part of this work was presented as a poster on the ESA 2016.

\section{Funding}

No funding in relation to this article.

\section{Conflicts of interest}

None.

\section{References}

1. Schauer PR, Bhatt DL, Kirwan JP, Wolski K, Brethauer SA, et al. (2014) Bariatric surgery versus intensive medical therapy for diabetes--3-year outcomes. $N$ Engl J Med 370: 2002-2013. [Crossref]

2. Crombie IK, Davies HT, Macrae WA (1998) Cut and thrust: antecedent surgery and trauma among patients attending a chronic pain clinic. Pain 76: 167-171. [Crossref]

3. Reddi D, Curran N (2014) Chronic pain after surgery: pathophysiology, risk factors and prevention. Postgrad Med J 90: 222-227. [Crossref]

4. Duale C, Ouchchane L, Schoeffler P, Group EI, Dubray C (2014) Neuropathic aspects of persistent postsurgical pain: a French multicenter survey with a 6-month prospective follow-up. J Pain 15: 24.e1-24.e20. [Crossref]

5. VanDenKerkhof EG, Peters ML, Bruce J (2013) Chronic pain after surgery: time for standardization? A framework to establish core risk factor and outcome domains for epidemiological studies. Clin J Pain 29: 2-8. [Crossref]

6. Kumar N, Soekarman D, Sing R, Bashah M, Abou Samra AB, Marcus MAE (2016) The peri-operative pain-curve of bariatric surgery. European Journal of Anaesthesiology 33. 
7. Arranz LI, Rafecas M, Alegre C (2014) Effects of obesity on function and quality of life in chronic pain conditions. Curr Rheumatol Rep 16: 390. [Crossref]

8. Carabotti M, Silecchia G, Greco F, Leonetti F, Piretta L, Rengo M, et al. (2013) Impact of laparoscopic sleeve gastrectomy on upper gastrointestinal symptoms. Obesity surgery 23: 1551-1557. [Crossref]

9. Montravers P, Augustin P, Zappella N, Dufour G, Arapis K, Chosidow D, et al. (2015) Diagnosis and management of the postoperative surgical and medical complications of bariatric surgery. Anaesth Crit Care Pain Med 34: 45-52. [Crossref]

10. Tabibian A, Grothe KB, Mundi MS, Kellogg TA, Clark MM, et al. (2015) Bariatric surgery patients' response to a chronic pain rehabilitation program. Obes Surg 25: 1917-1922. [Crossref]

11. Gribsholt SB, Pedersen AM, Svensson E, Thomsen RW, Richelsen B (2016) Prevalence of self-reported symptoms after gastric bypass surgery for obesity. JAMA Surg 151: 504-511. [Crossref]

12. Liberati A, Altman DG, Tetzlaff J, Mulrow C, Gøtzsche PC, et al. (2009) The PRISMA statement for reporting systematic reviews and meta-analyses of studies that evaluate health care interventions: explanation and elaboration. J Clin Epidemiol 62: e1-34. [Crossref]

13. Downs SH, Black N (1998) The feasibility of creating a checklist for the assessment of the methodological quality both of randomised and non-randomised studies of health care interventions. J Epidemiol Community Health 52: 377-384. [Crossref]

14. Manchikanti L, Hirsch JA, Cohen SP, Heavner JE, Falco FJ, et al. (2014) Assessment of methodologic quality of randomized trials of interventional techniques: development of an interventional pain management specific instrument. Pain physician 17: E263-90. [Crossref]

15. Manchikanti L, Hirsch JA, Heavner JE, Cohen SP, Benyamin RM, et al. (2014) Development of an interventional pain management specific instrument for methodologic quality assessment of nonrandomized studies of interventional techniques. Pain physician 17: E291-317. [Crossref]

16. Cabrera Schulmeyer MC, de la Maza J, Ovalle C, Farias C, Vives I (2010) Analgesic effects of a single preoperative dose of pregabalin after laparoscopic sleeve gastrectomy. Obesity surgery 20: 1678-1681. [Crossref]

17. Naja ZM, Khatib R, Ziade FM, Moussa G, Naja ZZ, et al. (2014) Effect of clonidine versus dexmedetomidine on pain control after laparoscopic gastric sleeve: A prospective, randomized, double-blinded study. Saudi J Anaesth 8: S57-62. [Crossref]

18. Cleveland EM, Peirce GS, Freemyer JD, Schriver JP, Ahnfeldt EP, Rice WV (2015) Prospective randomized double-blind controlled trial of continuous local anesthetic infusion to reduce narcotic use in laparoscopic sleeve gastrectomy. Surg Obes Relat Dis 11: 1152-1156. [Crossref]

19. Hassani V, Pazouki A, Nikoubakht N, Chaichian S, Sayarifard A, Shakib Khankandi A (2015) The effect of gabapentin on reducing pain after laparoscopic gastric bypass surgery in patients with morbid obesity: a randomized clinical trial. Anesthesiology and pain medicine 5: e22372. [Crossref]

20. Zeidan A, Al-Temyatt S, Mowafi H, Ghattas T (2013) Gender-related difference in postoperative pain after laparoscopic Roux-En-Y gastric bypass in morbidly obese patients. Obesity surgery 23: 1880-1884. [Crossref]

21. Albrecht E, Kirkham KR, Endersby RV, Chan VW, Jackson T, et al. (2013) Ultrasoundguided transversus abdominis plane (TAP) block for laparoscopic gastric-bypass surgery: a prospective randomized controlled double-blinded trial. Obesity surgery 23 : 1309-1314. [Crossref]

22. Weingarten TN, McGlinch BP, Liedl L, Kendrick ML, Kellogg TA, et al. (2015) Intranasal nicotine increases postoperative nausea and is ineffective in reducing pain following laparoscopic bariatric surgery in tobacco-Naive females: a randomized, double blind trial. Obesity surgery 25: 506-513.

23. Zotou A, Siampalioti A, Tagari P, Paridis L, Kalfarentzos F, Filos KS (2014) Does epidural morphine loading in addition to thoracic epidural analgesia benefit the postoperative management of morbidly obese patients undergoing open bariatric surgery? A pilot study. Obesity surgery 24: 2099-2108. [Crossref]

24. Novack V, Fuchs L, Lantsberg L, Kama S, Lahoud U, et al. (2011) Changes in headache frequency in premenopausal obese women with migraine after bariatric surgery: a case series. Cephalalgia 31: 1336-1342. [Crossref]

25. Burgerhart JS, van Rutte PW, Edelbroek MA, Wyndaele DN, Smulders JF, et al. (2015) Association between postprandial symptoms and gastric emptying after sleeve gastrectomy. Obesity surgery 25: 209-214. [Crossref]

26. Lloret-Linares C, Hirt D, Bardin C, Bouillot JL, Oppert JM, et al. (2014) Effect of a Roux-en-Y gastric bypass on the pharmacokinetics of oral morphine using a population approach. Clin Pharmacokinet 53: 919-930. [Crossref]

27. Ballem N, Yellumahanthi K, Wolfe M, Wesley MM, Clements RH (2009) Gastrointestinal symptom improvement after Roux-en-Y gastric bypass: long-term analysis. Surg Obes Relat Dis 5: 553-558. [Crossref]
28. Brissman M, Ekbom K, Hagman E, Mårild S, Gronowitz E, et al. (2017) Physical fitness and body composition two years after roux-en-y gastric bypass in adolescents. Obes Surg 27: 330-337. [Crossref]

29. Olbers T, Gronowitz E, Werling M, Marlid S, Flodmark CE, et al. (2012) Two-year outcome of laparoscopic Roux-en-Y gastric bypass in adolescents with severe obesity: results from a Swedish Nationwide Study (AMOS). Int J Obes (Lond) 36: 1388-1395. [Crossref]

30. Risstad H, Sovik TT, Hewitt S, Kristinsson JA, Fagerland MW, et al. (2015) Changes in health-related quality of life after gastric bypass in patients with and without obesityrelated disease. Obesity surgery 25: 2408-2416. [Crossref]

31. Kolotkin RL, Davidson LE, Crosby RD, Hunt SC, Adams TD (2012) Six-year changes in health-related quality of life in gastric bypass patients versus obese comparison groups. Surg Obes Relat Dis 8: 625-633. [Crossref]

32. Kroes M, Osei-Assibey G, Baker-Searle R, Huang J (2016) Impact of weight change on quality of life in adults with overweight/obesity in the United States: a systematic review. Curr Med Res Opin 32: 485-508. [Crossref]

33. Hachem A, Brennan L (2016) Quality of life outcomes of bariatric surgery: A systematic review. Obes Surg 26: 395-409. [Crossref]

34. Julia C, Ciangura C, Capuron L, Bouillot JL, Basdevant A, et al. (2013) Quality of life after Roux-en-Y gastric bypass and changes in body mass index and obesity-related comorbidities. Diabetes Metab 39: 148-154. [Crossref]

35. Dixon JB, Eaton LL, Vincent V, Michaelson R (2016) LAP-BAND for BMI 30-40: 5-year health outcomes from the multicenter pivotal study. Int J Obes (Lond) 40: 291 298. [Crossref]

36. Steele KE, Prokopowicz GP, Chang HY, Richards T, Clark JM, et al. (2012) Risk of complications after bariatric surgery among individuals with and without type 2 diabetes mellitus. Surg Obes Relat Dis 8: 305-330. [Crossref]

37. Gerbershagen HJ, Aduckathil S, van Wijck AJ, Peelen LM, Kalkman CJ, Meissne W (2013) Pain intensity on the first day after surgery: a prospective cohort study comparing 179 surgical procedures. Anesthesiology 118: 934-944. [Crossref]

38. Lakdawala M, Agarwal A, Dhar S, Dhulla N, Remedios C, Bhasker AG (2015) Single-incision sleeve gastrectomy versus laparoscopic sleeve gastrectomy. A 2-year comparative analysis of 600 patients. Obes Surg 25: 607-614. [Crossref]

39. Liu XZ, Fan J, Zhang YQ, Xu MJ, Zhao DB (2016) Single-incision or conventional laparoscopic adjustable gastric banding: A systematic review. Minimally invasive therapy \& allied technologies 25: 62-69.

40. McGuire L, Heffner K, Glaser R, Needleman B, Malarkey W, et al. (2006) Pain and wound healing in surgical patients. Ann Behav Med 31: 165-172. [Crossref]

41. Cregg R, Anwar S, Farquhar-Smith P (2013) Persistent postsurgical pain. Curr Opin Support Palliat Care 7: 144-152. [Crossref]

42. King WC, Hsu JY, Belle SH, Courcoulas AP, Eid GM, et al. (2012) Pre- to postoperative changes in physical activity: report from the longitudinal assessment of bariatric surgery-2 (LABS-2). Surg Obes Relat Dis 8: 522-532. [Crossref]

43. Fletcher D, Stamer UM, Pogatzki-Zahn E, Zaslansky R, Tanase NV, et al. (2015) Chronic postsurgical pain in Europe: An observational study. Eur J Anaesthesiol 32: 725-734. [Crossref]

44. Wasowicz-Kemps DK, Bliemer B, Boom FA, de Zwaan NM, van Ramshorst B (2006) Laparoscopic gastric banding for morbid obesity: outpatient procedure versus overnight stay. Surg Endosc 20: 1233-1237. [Crossref]

45. Lakdawala MA, Muda NH, Goel S, Bhasker A (2011) Single-incision sleeve gastrectomy versus conventional laparoscopic sleeve gastrectomy--a randomised pilot study. Obes Surg 21: 1664-1670. [Crossref]

46. Eidy M, Pazouki A, Raygan F, Ariyazand Y, Pishgahroudsari M, Jesmi F (2014) Functional abdominal pain syndrome in morbidly obese patients following laparoscopic gastric bypass surgery. Arch Trauma Res 3: e13110. [Crossref]

47. Vage V, Sande VA, Mellgren G, Laukeland C, Behme J, Andersen JR (2014) Changes in obesity-related diseases and biochemical variables after laparoscopic sleeve gastrectomy: a two-year follow-up study. BMC Surg 14: 8. [Crossref]

Copyright: (C2017 Kumar N. This is an open-access article distributed under the terms of the Creative Commons Attribution License, which permits unrestricted use, distribution, and reproduction in any medium, provided the original author and source are credited. 